\title{
Analysis of Natural Vibration Characteristics of the Steel Tubular Tower for Horizontal Axis Wind Turbine
}

\author{
Zhenhua Liu" ${ }^{1,}$, Lili Zhang ${ }^{1, a}$ and Juan $\mathrm{Li}^{1, \mathrm{a}}$ \\ ${ }^{1}$ School of Civil Engineering, Shandong University, Jinan 250061, China \\ agergina@126.com
}

Keywords: Steel Tubular Tower, Natural Vibration Characteristics, Frequency, Vibration mode Abstract. Based on the principle of dynamic finite element theory, the horizontal axis wind turbine $600 \mathrm{~kW}$ tower models were established in this paper to study the dynamic characteristics and influencing factors of the wind turbine tower. The author studied three meaningful vibration modes: lateral flexural vibration modes, back and forth flexural vibration modes and torsional vibration modes.

\section{Introduction}

The vibration characteristics of the wind turbine tower is its inherent mechanical properties of an extremely important, it directly affects the effect of horizontal loads, such as wind and seismic loads these two types of dynamic effects in the tower itself. But also the vibration characteristics tower is the important indicators to measure if the quality of tower match with the stiffness, the stiffness is reasonable, which is the core of the structure of dynamic analysis ${ }^{[1]}$.

\section{Finite element analysis of the vibration characteristics of steel tower}

$600 \mathrm{~kW}$ horizontal axis wind turbine tower is steel tapered tube. In accordance with the design data, the steel tower is $38.5 \mathrm{~m}$ high, the bottom diameter is $3.0 \mathrm{~m}$, the diameter of the top is $1.928 \mathrm{~m}$, and the material is $\mathrm{Q} 345 \mathrm{D}$ steel. The tower is divided into six, between that make use of flange to connect, the geometric model of tower, the finite element model of tower with nacelle and the finite element model of independent tower are shown in Fig.1 3.

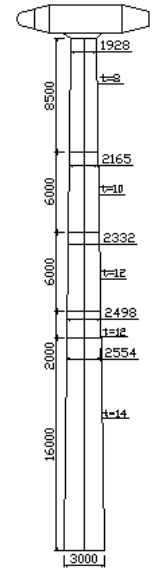

Fig. 1

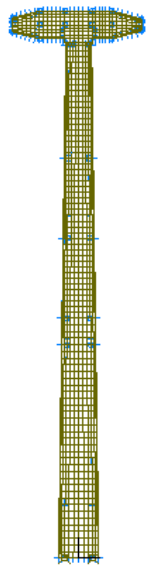

Fig. 2

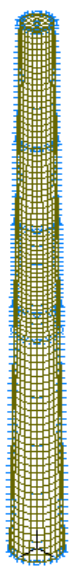

Fig. 3

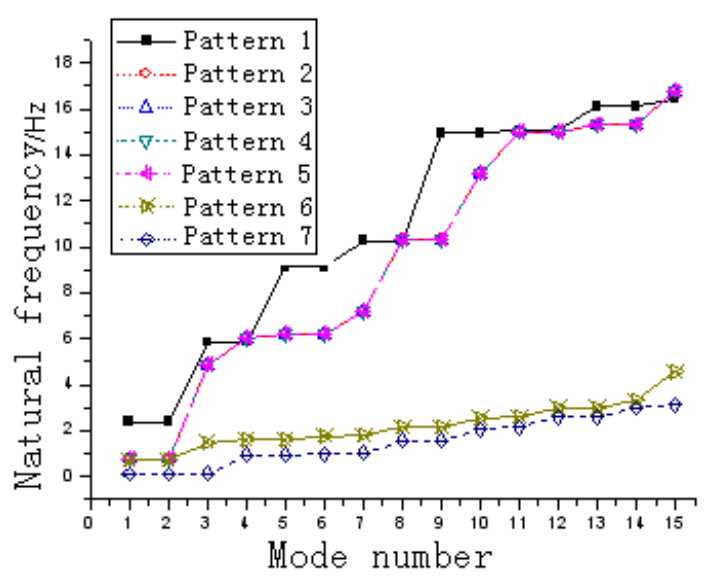

Fig.4

Fig. 1 the geometric model of tower; Fig.2 the finite element model of tower with nacelle ;Fig.3 the finite element model of independent tower ;Fig.4 the change curveof the natural frequency. 
The simplifying assumptions of the Finite Element Modeling are made as following:

(1) The nacelle was reduced to be quality mass which action on in the top of the tower.

(2) Impeller simplified the mass of the nacelle cantilever side placed at the top of the tower and the tower simplify the variable cross-section of the tube shell and fixed connector with the nacelle at the top of the tower.

(3) The tower is used shell element model, the top of the tower using 3D solid element model.

In order to design more reliable, we should take into account of foundation stiffness in the design of tower, estimate the deviation between the actual natural frequency value of the tower and the calculated values which caused by the effects of foundation stiffness ${ }^{[2-3]}$. Five analysis programs of $\mathrm{JC} 1, \mathrm{JC} 2, \mathrm{JC} 3, \mathrm{JC} 4, \mathrm{JC} 5$ based on the foundation stiffness were considered in this article. The size of the foundation of JC1, JC2, JC3 is $5 \mathrm{~m} \times 5 \mathrm{~m} \times 1.8 \mathrm{~m}, 5 \mathrm{~m} \times 5 \mathrm{~m} \times 1.8 \mathrm{~m}, 5 \mathrm{~m} \times 5 \mathrm{~m} \times 1.8 \mathrm{~m}$ respectively. The calculated of foundation stiffness and added mass could reference the suggestion of Mulliken and Karabalis ${ }^{[4]}$. The foundation size of JC4 and JC5 are the same with JC3. The self-weight of foundation is $21 \mathrm{kN} / \mathrm{m} 3$, Poisson's ratio is 0.3 and the shear modulus is $520 \mathrm{MPa}$. The results are shown in Table 1.

Table 1 Five-foundation stiffness and added mass parameter table

\begin{tabular}{|c|c|c|c|c|}
\hline \multicolumn{2}{|c|}{ Size of foundation } & Horizontal & Vertical & Rocking \\
\hline \multirow{2}{*}{ JC1 1} & Static stiffness & $7.0353 \times 10^{9}[\mathrm{~N} / \mathrm{m}]$ & $8.729 \times 10^{9}[\mathrm{~N} / \mathrm{m}]$ & $4.643 \times 10^{10}[\mathrm{~N} \bullet \mathrm{m} / \mathrm{rad}]$ \\
\cline { 2 - 5 } & Add mass & $2.12 \times 10^{4}[\mathrm{~kg}]$ & $7.068 \times 10^{4}[\mathrm{~kg}]$ & $9.15 \times 10^{4}\left[\mathrm{~kg} \bullet \mathrm{m}^{2}\right]$ \\
\hline \multirow{2}{*}{$\mathrm{JC} 2$} & Static stiffness & $1.407 \times 10^{10}[\mathrm{~N} / \mathrm{m}]$ & $1.746 \times 10^{10}[\mathrm{~N} / \mathrm{m}]$ & $3.714 \times 10^{11}[\mathrm{~N} \bullet \mathrm{m} / \mathrm{rad}]$ \\
\cline { 2 - 5 } & Add mass & $1.77 \times 10^{5}[\mathrm{~kg}]$ & $5.93 \times 10^{5}[\mathrm{~kg}]$ & $1.19 \times 10^{7}\left[\mathrm{~kg} \bullet \mathrm{m}^{2}\right]$ \\
\hline \multirow{2}{*}{ JC3 } & Static stiffness & $1.759 \times 10^{10}[\mathrm{~N} / \mathrm{m}]$ & $2.182 \times 10^{10}[\mathrm{~N} / \mathrm{m}]$ & $7.254 \times 10^{11}[\mathrm{~N} \bullet \mathrm{m} / \mathrm{rad}]$ \\
\cline { 2 - 5 } & Add mass & $3.47 \times 10^{5}[\mathrm{~kg}]$ & $1.158 \times 10^{6}[\mathrm{~kg}]$ & $3.617 \times 10^{7}\left[\mathrm{~kg} \bullet \mathrm{m}^{2}\right]$ \\
\hline \multirow{2}{*}{ JC4 } & Static stiffness & $1.759 \times 10^{10}[\mathrm{~N} / \mathrm{m}]$ & $10^{7}[\mathrm{~N} / \mathrm{m}]$ & $7.254 \times 10^{11}[\mathrm{~N} \bullet \mathrm{m} / \mathrm{rad}]$ \\
\cline { 2 - 5 } & Add mass & $3.47 \times 10^{5}[\mathrm{~kg}]$ & $1.158 \times 10^{6}[\mathrm{~kg}]$ & $3.617 \times 10^{7}\left[\mathrm{~kg} \bullet \mathrm{m}^{2}\right]$ \\
\hline \multirow{2}{*}{ JC5 } & Static stiffness & $1.759 \times 10^{10}[\mathrm{~N} / \mathrm{m}]$ & $10^{5}[\mathrm{~N} / \mathrm{m}]$ & $7.254 \times 10^{11}[\mathrm{~N} \bullet \mathrm{m} / \mathrm{rad}]$ \\
\cline { 2 - 5 } & Add mass & $3.47 \times 10^{5}[\mathrm{~kg}]$ & $1.158 \times 10^{6}[\mathrm{~kg}]$ & $3.617 \times 10^{7}\left[\mathrm{~kg} \bullet \mathrm{m}^{2}\right]$ \\
\hline
\end{tabular}

When analyzing the vibration characteristics of the Wind turbine tower, the calculation patterns can be categorized under 3 patterns. Pattern 1: considering the nacelle and the impeller, rigid foundation, pattern 2: Considering the nacelle and the impeller, rigid foundation and pattern 3 7: consider the nacelle and the impeller, the basis is JC1 JC5.

\section{Analysis on Natural Frequencies}

In this paper, the vibration characteristic of the wind turbine tower was calculated using the finite element software ADINA considering the seven kinds of patterns mentioned above.

For the purposes of comparison, the change curve of the natural frequency for the wind turbine tower from pattern 1 to pattern 7 following the vibration mode, shown in Fig.4.

Analysis and Conclusion:

(1) Comparing natural frequency of the 1-15 modes, the frequency value increases with the vibration mode, and the first natural frequency is the smallest.

(2) The natural frequency of wind turbine tower increases with the foundation stiffness.

(3) From the calculation results, it can be learned that the impact of the design proposal of the tower foundation on the natural frequencies of the tower structure is less than $1 \%$, while the impact 
of engineering geological conditions has reached $84.23 \%$, it can be seen that the extent of the foundation soil moisture or soft rock type seriously impact on the vibration characteristics of the tower structure.

\section{The analysis of vibration mode}

The top ten order vibration mode map of calculation patterns 1 and 7are shown in Fig.5 6.
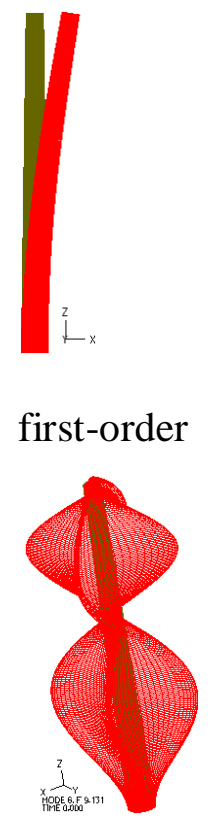

Sixth-order
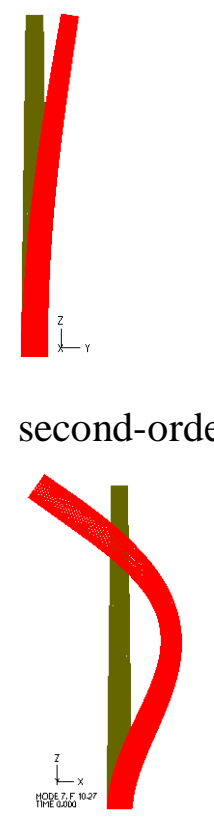

seventh-order
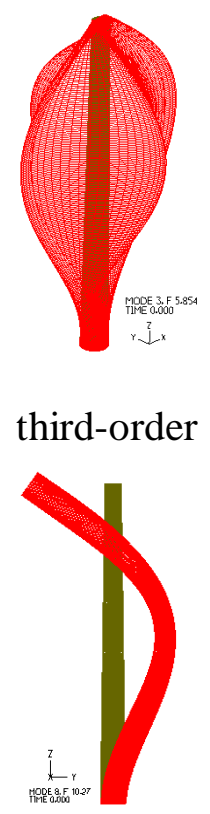

eighth-order
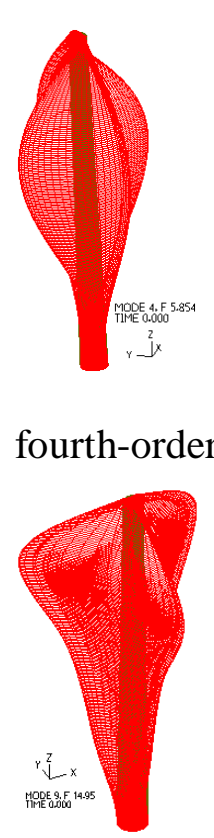

Ninth-order
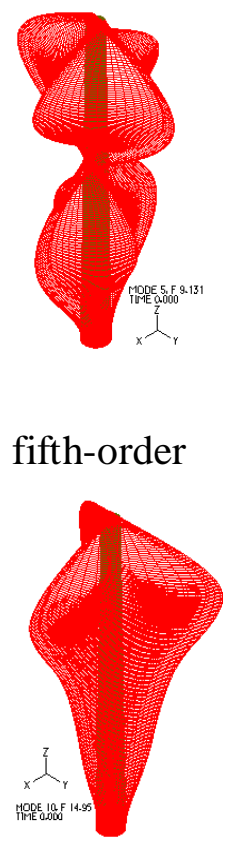

Tenth-order

Fig. 5 the top ten order vibration modes of Calculation Pattern 1

As seen from Fig.5, for Pattern 1 the first-order vibration mode is the first order bending vibration of the $\mathrm{XZ}$ plane. The second-order vibration mode is the first-order bending vibration mode of the $\mathrm{YZ}$ plane. The third and fourth order vibration modes are the first-order torsional vibration of the rotating plane. The fifth and sixth-order vibration modes are the second-order torsional vibration of the rotating plane. The seventh and eighth-order vibration modes are the second-order bending vibration of the XZ plane and YZ-plane. The ninth and tenth-order vibration mode is the third-order torsional vibration of the rotation-plane.

As seen from Fig.6, for Pattern 7, the first-order and second-order vibration modes are the first order translation vibration of the $\mathrm{XZ}$ plane and $\mathrm{YZ}$ plane respectively. The third order vibration mode which is different from the third order vibration mode of Pattern 1 and Pattern 2, is vertical vibration. The fourth-order and fifth-order vibration modes are the second-order bending vibration of the XZ plane and YZ-plane. From sixth-order to tenth-order vibration modes are the torsional vibration of the rotation-plane, and which break out in the bottom of the tower. 


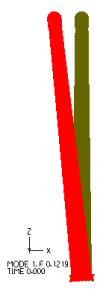

first-order

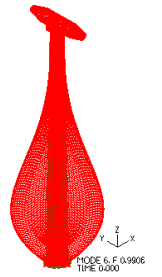

Sixth-order

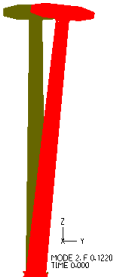

second-order

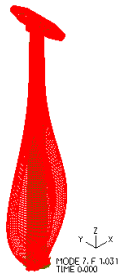

seventh-order

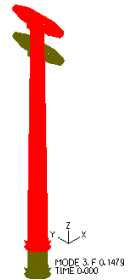

third-order

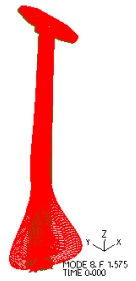

eighth-order

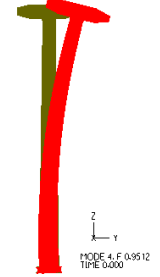

fourth-order

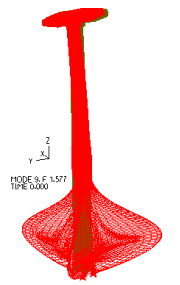

Ninth-order

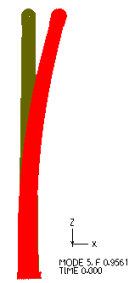

fifth-order

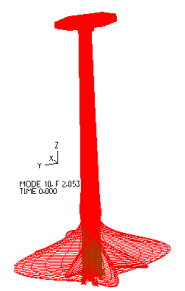

Tenth-order

Fig. 6 the top ten order vibration modes of Calculation Patterns 7

\section{Conclusion}

From the above analysis, when carrying out on the vibration characteristics analysis of the steel tower, in addition to establish a reasonable model of the tower, it must to consider the quality of the nacelle and the impeller and the foundation stiffness of the tower, and to ensure the accuracy of these data. The quality calculation of the components inside the nacelle shall be carried out before designing the tower, and provide reliable data for the calculation of the natural frequencies. It is clear from the analysis results of the natural frequency and inherent vibration modes that the top two order modes are bending vibration in XZ plane and YZ-plane, and the top two order frequency is very small, the third-order vibration mode is the first-order torsional vibration in rotating plane, and the corresponding natural frequency is 6.3 times of the second-order natural frequency, indicating that the frequency of reverse vibration and the frequency of bending vibration are very different, frequency mixing and shock excitation of the steel tube tower would not occur. At the same time it also shows that the torsional of stiffness the structure is large and which is one of the significant advantages of the tube shell structure.

\section{References}

[1] Zhaomin Wang, Renle Ma. Tower structure [M]. Beijing: Science Press,2004:113-114.

[2] GB/T 19072-2003. Wind turbine tower. China Machinery Industry Federation, 2003.

[3] JB/T 10300-2001.Wind turbine design requirements, China Machinery Industry Association, 2001.

[4] Mulliken JS, Karabalis DL. Discrete model for dynamic through-the-solid coupling of 3-D foundations and structure Earthquake Engng. Struct. Dyn. 27,687-710 (1998). 